\title{
TEMPERATURE/BODY SIZE INTERACTIONS AND SPECIES INTERACTIONS IN MONTANE PONDS In GRAND Teton NATIONAL PARK
}

\author{
BRUCE WOODWARD $\downarrow$ DEPARTMENT OF BIOLOGY \\ UNIVERSITY OF NEW MEXICO • ALBUQUERQUE \\ SANDRA MITCHELL $\bullet$ DEPARTMENT OF BIOLOGY \\ WESTERN WYOMING COLLEGE $\downarrow$ ROCK SPRINGS
}

\section{SUMMARY OF RESEARCH ACCOMPLISHMENTS}

We visited Grand Teton National Park in May, June and July 1991 to begin research on species interactions in shallow montane ponds. Our primary interests were in how body size variation influences species interactions, and how temperature influences body size and thus species interactions. Our goal in the first year was to explore the extant variation in temperature regimes and body sizes of potentially interacting species, and examine some of these species interactions.

Pseudacris triseriata (the Northern Chorus Frog) was our focal species. Chorus frogs turned out to be relatively abundant at Grand Teton National Park, and occurred in most montane ponds. Breeding started on 21 May and continued for at least two weeks. Psuedacris were present in natural ponds as tadpoles up through mid July. Our research focused on the larval or tadpole stage. Several species of macro-invertebrates or small vertebrates also occurred in these ponds. A small handful of these species attracted our attention. These species either were quite abundant and appeared to interact strongly with chorus frog tadpoles or other species that interact strongly with chorus frog tadpoles, or exhibited strong across pond patterns suggesting avoidance of chorus frog tadpoles.

Two species of snails, one caddisfly larvae, and the Pseudacris tadpoles were the major herbivores in the system and could be quite abundant in any given pond. All three species are raspers and feed on the periphyton. Fairy shrimp also were common in some ponds. These are filter feeders that feed on plants, animals and protists. These four groups (especially the raspers) are likely competitors if resources are limiting. We quantified species densities in several ponds. The four grazers were all commonly present in the same pond but one group was typically much more abundant than the others in any given pond. This pattern is interesting and something we hope to pursue further. Whether this pattern is an epiphenomenon of our small sample size, due to undetected differences in habitat requirements, or a result of species interactions is not yet clear.

There were two major predators in the system. Ambystoma tigrinum (Tiger Salamanders) were present in the ponds both as developing larvae, and less commonly as adults. The adults fed heavily on the snails and probably also fed on the tadpoles. The larvae fed heavily on the tadpoles, but were too small (given their relative sizes this year) to feed on the 
snails. Neither the adults or the larvae appeared to feed on the caddisfly larvae. The other predator was a larval insect (tentatively a Corydalid or Dyticid larvae) that was $25-40 \mathrm{~mm}$ long. This predator fed on tadpoles, but not caddisflys or snails.

We collected a sample of predators and potential prey and placed them together to see who would eat whom. In addition we performed a small series of prey choice tests. In some tests the predator was offered a choice between different species, in others between prey of different sizes of the same species. Many aquatic predators including tiger salamanders and predacious insect larvae commonly feed on prey 10 to $50 \%$ of their body sizes. At these relative size ratios, slight differences in prey size can have major effects on the ability of the predator to capture and subdue the prey. This favors the evolution of strong prey preferences based on prey body size. Tiger salamander larvae disproportionately preyed on chorus frog tadpoles over damselfly larvae (roughly similar sized and both abundant potential prey), and disproportionately preyed on small relative to medium sized chorus frog tadpoles.

We attempted to test for competitive interactions among caddisfly larvae and chorus frog tadpoles by performing an experiment in field cages. Unfortunately the pond dried faster than anticipated and the cages were left high and dry between two of our visits to the pond. We also performed an experiment to test for competitive interactions between one snail species and the chorus frog tadpoles. We superimposed the presence or absence of tiger salamander larvae (a tadpole predator) onto this competitive experiment. We have not analyzed the results of this experiment yet.
Temperature variation was examined in several ponds and was pronounced. Temperatures varied up to $5 \mathrm{C}$ from the surface to the pond bottom (even though ponds were less than $1 \mathrm{~m}$ deep). Temperature also varied up to $5 \mathrm{C}$ at the surface over the course of the day. Temperature varied up to $4 \mathrm{C}$ between shady and sunny areas of a pond. Finally, measurements made at the same time documented up to $10.2 \mathrm{C}$ differences in temperature between ponds.

\section{$\checkmark$ SIGNIFICANCE OF OBSERVATIONS}

Our preliminary research reveals that there is sizeable temporal and spatial temperature variation in small montane ponds. Superimposed on this variation is variation across ponds in the body sizes of Pseudacris tadpoles and their potential competitors or predators. This appears to be a dynamic system in which to explore the interactions between temperature variation, body size variation, and the outcome of species interactions. We plan to continue this line of research.

\section{$\checkmark \quad$ PROBLEMS}

We anticipate no problems in continuing this research.

\section{- WORK REMAINING}

The only work remaining on this project (for this funding year) is too analyze the competition/predation experiment and write a final report. 